\title{
An Observational Study on the Sexual Assault Victims in the Year 2018 at Tartiary Health Care Center of Rajasthan
}

\author{
Mahendra Singh $^{1}$, R.K Punia ${ }^{2}$, Deepali Pathak ${ }^{3}$, Shashank Sharma ${ }^{1}$ \\ ${ }^{1}$ Senior Demonstrator, ${ }^{2}$ Senior Professor, ${ }^{3}$ Associate Professor (Forensic Medicine) SMS Medical College, Jaipur
}

\begin{abstract}
Introduction:-Sexual assaults are inhuman crimes against individual as well as the whole society. This study was thus initiated to obtain statistical pattern of sexual assaults pertaining to analyze various aspects including socio-demography and victim assailant relation, other relevant factors.
\end{abstract}

\section{Materials and Method:-}

Inclusion Criteria :-all the victims/sexual offence survivors examined at SMS Medical College, Jaipur during 1st January 2018 to 31 st December 2018

Exclusion Criteria:- all the alleged cases of sexual offence whom consent could not be obtained.

Results:- total 60 cases were studied. The mean age of the victims in present study was 20.98 years. $73.33 \%$ victims were from urban regions. $50 \%$ victims were educated. $70 \%$ victims in the present study were married. Most common place of commission of the crime was the victim's own home (46.67\%) . 43.34\% victims reported within one week time period from the incidence. $88.33 \%$ victims were assaulted by a single person. $76.67 \%$ victims were assaulted by familiar persons. In $51.67 \%$ cases, the victim had been assaulted multiple times. In $85 \%$ cases, there was peno-vaginal intercourse. $71.67 \%$ cases had no injury in the present study. $3.33 \%$ victims got pregnant after the sexual assault.

Conclusion:- Females of reproductive age group were the most common victims in the present study. Familiar persons committed the crime in most cases and victim's home was the most common site of occurrence. There was delayed reporting of the crime in most cases which was the main reason for loss of vital trace evidences.

Suggestions:- Strict adherence to protocols for medical examination of victims of sexual assaults should be mandatory. Sex education should be provided to school students of teenage to increase awareness regarding medical and legal issues related to such events to increase the reporting of this crime.

Key Words:- sexual offences, Hymen, victim, accused, POCSO.

\section{Introduction}

Sexual assaults are inhuman crimes directed against individual as well as the whole society1. Sexual offence

\author{
Corresponding Author: \\ Dr. R.K. Punia- \\ Sr. Professor, (Forensic Medicine) SMS Medical \\ College, Jaipur \\ Phone no. 9414780654 \\ Email Id -rkpunia86@gmail.com
}

may be associated with physical violence also2. No age or gender stands bar to this crime3. Rape is usually underreported crime experienced by women in all sections of the society and obtaining an accurate measurement of sexual assault is a challenge4. Sexual assault, a form of sexual violence, often used synonymously with rape, could include anything from touching another person's body in a sexual way without the person's consent to forced sexual intercourse - oral and anal sexual acts, child molestation, fondling and attempted rape. The Prevention of children against sexual offences act (POCSO ACT, 2012)5,6 has been added as well as 
section 375 IPC and 376 IPC amendments have been done to combat any form of sexual intentions directed against children and females irrespective of gender. Multidisciplinary approach is required for investigation of these cases 7

This study was thus initiated to observe the pattern of sexual assaults pertaining to analyze all aspects including socio-demography and victim assailant relation, other relevant factors and further recommendations.

\section{Materials and Method}

1. Total 68 victims of sexual assault reported at Department of Forensic Medicine, SMS Medical College and attached Hospitals, Jaipur included as Hospital Based observational study universe

2. 60 Victims of sexual assault/ relatives who consented were included for study. Out of them there were 53 survivors and 07 non survivor victims who suffered fatal injuries in the incident.

3. Only two male victims of sexual offence were reported at SMS hospital during the study period (03.33\%), The number of female victims among study group population have been reported to be $96.66 \%$

4. All the cases were interviewed on socio demographic profile and relevant factors according to the proposed Proforma. The medico-legal examination for bodily injuries and genital examination for rape was conducted along with the doctors preparing the medicolegal reports.
5. Continuous variables were summarized as mean and standard deviation whereas nominal/categorical variables as proportion. Chi-square test was used for analysis of nominal categorical variables. Statistical analysis was conducted using Medcalc 16.4 versions software

\section{Observations}

1. Out of 60 total case 44 victims $(73.33 \%)$ were from urban region and rest $26.67 \%$ victims from rural status. the majority of victims were unmarried being $70 \%$ and married being $30 \%$. majority of victims $(50 \%)$ were adequately educated, secondary or higher as per their age $\&$ Only $25 \%$ victims ( 15 out of 60 ) were educated below secondary education and $25 \%$ of them totally illiterate. Majority of victims in the present study were students (35\%) followed by housewives $(23.34 \%)$. hymen was recently torn in $15 \%$ cases and old insignificant tears in $65 \%$ cases. The hymen was intact in $13.33 \%$ cases. The total number of cases with ruptured hymen was $80 \%$.Two cases of sexual assault got pregnant after the assault $(03.33 \%)$.

2. In $85 \%$ cases in the present study natural sexual intercourse offence was committed whereas there were $08.33 \%$ cases of unnatural sex booked under Section 377 of the Indian Penal Code, 1860 (peno-oral sex in $03.33 \%$ cases and peno-anal sex in 5\% cases). In rest $6.67 \%$ cases there had occurred touching, fingering etc. to the external genitalia.

Table : 1: Distribution of Victims according to Age and Gender

\begin{tabular}{|l|l|l|l|}
\hline Age Group (Years) & Male & Female & Total (\%) \\
\hline $0-5$ & 0 & 05 & $05(08.33 \%)$ \\
\hline $6-<18$ & 02 & 20 & $22(36.67 \%)$ \\
\hline $18-49$ & 0 & 31 & $31(51.67 \%)$ \\
\hline$>50$ & 0 & 02 & $02(03.33 \%)$ \\
\hline Total (\%) & $02(03.33 \%)$ & $58(96.67 \%)$ & $60(100 \%)$ \\
\hline
\end{tabular}


Table 2: Alleged place of incidence of sexual assault

\begin{tabular}{|l|l|}
\hline Alleged place of incidence & Total (\%) \\
\hline Home & $28(46.67 \%)$ \\
\hline Neighborhood & $12(20 \%)$ \\
\hline Hotel & $05(08.33 \%)$ \\
\hline Home of assailant & $05(08.33 \%)$ \\
\hline Unknown & $03(05 \%)$ \\
\hline Office/ factory & $02(03.33 \%)$ \\
\hline Fields & $02(03.33 \%)$ \\
\hline Variable Multiple & $02(03.33 \%)$ \\
\hline School & $01(01.68 \%)$ \\
\hline Total & 60 \\
\hline
\end{tabular}

Table 3: TIME Gap between incidence of sexual assault and Medico-legal examination

\begin{tabular}{|l|l|}
\hline Time Period & Total (\%) \\
\hline Same day & $03(05.00 \%)$ \\
\hline 2nd day & $09(15.00 \%)$ \\
\hline 3rd day & $05(08.33 \%)$ \\
\hline 4th day & $02(03.33 \%)$ \\
\hline 5 th-7th day & $07(11.67 \%)$ \\
\hline $1-4$ week & $05(08.33 \%)$ \\
\hline $1-6$ month & $14(23.34 \%)$ \\
\hline$>6$ month & $15(25.00 \%)$ \\
\hline Total & $60(100 \%)$ \\
\hline
\end{tabular}

Table 4: Distribution of cases of sexual assault according to number of Assailants

\begin{tabular}{|l|l|}
\hline Number of Assailants & Total (\%) \\
\hline One & $53(88.33 \%)$ \\
\hline Two & $03(05 \%)$ \\
\hline Three & $04(06.67 \%)$ \\
\hline Total & $60(100 \%)$ \\
\hline
\end{tabular}


Table 5: Relation between victims and the Assailant

\begin{tabular}{|l|l|}
\hline Relation to Assailants & Total (\%) \\
\hline Neighbor & $16(26.67 \%)$ \\
\hline Stranger & $14(23.34 \%)$ \\
\hline Close Friend & $08(13.33 \%)$ \\
\hline Co-worker or Senior at Job & $08(13.33 \%)$ \\
\hline In Law relatives & $05(08.33 \%)$ \\
\hline Relative or Friend of Relative & $04(06.67 \%)$ \\
\hline Husband & $03(05 \%)$ \\
\hline Father or Paternal Uncle & $02(03.33 \%)$ \\
\hline Total & 60 \\
\hline
\end{tabular}

Table 6: Distribution of cases of sexual assault according to the presence or absence of Genital and/ or Bodily injuries

\begin{tabular}{|l|l|l|l|l|l|}
\hline Sn & \multicolumn{2}{|l|}{ Genital Injuries } & \multicolumn{2}{l|}{ Bodily Injuries } & Total \\
\hline & Present & Absent & Present & Absent & \\
\hline 1 & & YES & & YES & $46(76.67 \%)$ \\
\hline 2 & & YES & YES & & $8(8.33 \%)$ \\
\hline 3 & YES & & & YES & $3(5 \%)$ \\
\hline 4 & YES & & YES & & $9(15 \%)$ \\
\hline
\end{tabular}

\section{Discussion}

1. Female out-proportionate the male in number as victim of sexual offences. The mean age of the victims in present study was 20.98 years. Majority of the victims in the present study were between 18 to 49 years of age $(51.67 \%)$ followed by 6 to 18 years of age (31.67\%). There were $08.33 \%$ victims who were less than five years of age.

2. $46.67 \%$ victims were sexually assaulted in their own homes in the present study followed by next $20 \%$ sexual assaults in neighborhood. Other common sites of occurrence of these crimes were hotels $(08.33 \%)$ followed by fields and offices ( $03.33 \%$ each); and, in 5\% cases the place of assault remained undetermined owing to drugging of the victim or death of victim.
3. In the present study, only $5 \%$ victims had reported the crime on the same day. Another 15\% had reported on second day, $08.33 \%$ on third day and rest $15 \%$ between fourth to seventh days.

4. In $88.33 \%$ cases the victims had been assaulted by a single offender. In five percent cases there were two assailants and rest $6.67 \%$ cases were gang rape cases. Seven victims were killed after the episode of sexual assault (11.67\%). 76.67\% victims knew their assailants in the present study and $23.33 \%$ victims were assaulted by strangers. Amongst the known offenders, neighbors were the most common assailants $(34.78 \%)$ followed by close friends and coworkers (13.33\% each). Relatives or their acquaintances comprised the remaining $30.44 \%$ cases 
5. In $41.66 \%$ cases the crime had occurred only once and was reported. $51.67 \%$ victims suffered multiple times before reporting the crime.

6. In the present study, there was no injury at all in $71.67 \%$ cases. There were isolated bodily (extra-genital) injuries in $08.33 \%$ cases and isolated genital injuries in $5 \%$ cases. $15 \%$ victims had both genital as well as extra genital injuries.

\section{Conclusion}

Sexual violence against women and children is a major public health issue. Females of reproductive age group were the most common victims in the present study. Most commonly affected ages were 17 and 22 years.

Familiar persons committed the crime in most cases and victim's home was the most common site of occurrence.

In majority of cases, there was no evidence of forceful sexual intercourse but still opinion of penetrative sexual assault was concluded in $45 \%$ cases.

There was delayed reporting of the crime in most cases which was the main reason for loss of vital trace evidences. This is also indicative of underreporting of this crime owing to social stigma.

Strict adherence to protocols for medical examination of victims of sexual assaults should be mandatory along with the development of a referral system to with fully equipped expert medico-legal teams for examination. sex education should be provided to school students of teenage to increase awareness regarding medical and legal issues related to such events to increase the reporting of this crime.
Suggestions:-

- DES prophylactic therapy as post coital drug should be adviced 1

\section{Acknowledgement: Nil \\ Conflict of Interest: Nil}

Source of Funding: Self

Ethical Clearance : Ethical clearance for the study was obtained from Institute Ethics Committee SMS Medical College, and Attached group of Hospitals, Jaipur

\section{References}

1. Malhotra N, Sood M. Sexual assault, a neglected public health problem in developed world. Int Journ Obstet and Gynaecol. 2001; 71:257-8.

2. Riggs N, Houry D, Long G, Markovchick V, Feldhaus K M. Analysis of 1076 cases of sexual assault. Ann Emerg Med 2000; 35:358-62.

3. Du Mont J and Parnis D. Sexual assault and legal resolution; Querying the medical collection of Forensic evidence. Med Sci Law. 2000; 19(4): 77992.

4. Fimate L, Devi Th M. An analytical study of rape in Manipur. Int Journ Med Toxicol and legal Med. 1998; 1:1-2.

5. Bhardwaj DN, Sharma RK, Sagar MS, Murty OP. Study of sexual offences victims in South Delhi. J Forensic Med Toxicol. 1995; 12 (3\&4): 33-4.

6. Sagar MS, Sharma RK, Dogra TD. Sexual offences in South Delhi. J Forensic Med Toxicol. 1992; 9: 8-11.

7. Hazelwood RR and Burgess AW. Practical aspects of Rape Investigation-A multidisciplinary approach. 2nd ed. Florida; CRC Press, 1995. p. 258. 